$\sqrt[3]{2019} \cdot 92$

\title{
Analysis of Cadmium and Copper in Cyanide Plating Solutions by the Inductively Coupled Argon \\ Plasma Spectrometer
}

G. R. Osbourn

KCP-613-4421

Published October 1991

Final Report

Prepared for the United States Department of Energy Under Contract Number DE-ACO4-76-DP00613.

\section{Allied-Signal Aerospace Company}




\section{DISCLAIMER}

This report was prepared as an account of work sponsored by an agency of the United States Government. Neither the United States Government nor any agency thereof, nor any of their employees, makes any warranty, express or implied, or assumes any legal liability or responsibility for the accuracy, completeness, or usefulness of any information, apparatus, product, or process disclosed, or represents that its use would not infringe privately owned rights. Reference herein to any specific commercial product, process, or service by trade name, trademark, manufacturer, or otherwise, does not necessarily constitute or imply its endorsement, recommendation, or favoring by the United States Government or any agency thereof. The views and opinions of authors expressed herein do not necessarily state or reflect those of the United States Government or any agency thereof.

Printed in the United States of America.

This report has been reproduced from the best available copy.

Available to DOE and DOE contractors from the Office of Scientific and Technical Information, P. O. Box 62, Oak Ridge, Tennessea 37831; prices available from (615) 576-8401, FTS 626-8401.

Available to the public from the National Technical Information Service, U. S. Department of Commerce, 5285 Port Royal Rd., Springfield, Virginia 22161. 
Distribution DE92 002082

ANALYSIS OF CADMIUM AND COPPER IN CYANIDE PLATING SOLUTIONS BY THE INDUCTIVELY COUPLED ARGON PLASMA SPECTROMETER

G. R. Osbourn

Published October 1991

Final Report

G. R. Osbourn, Project Leader 
ANALYSIS OF CADMIUM AND COPPER IN CYANIDE PLATING SOLUTIONS BY THE INDUCTIVELY COUPLED ARGON PLASMA SPECTROMETER

KCP-613-4421, Final Report, Published October 1991

Prepared by G. R. Osbourn

Methods have been developed for the analysis of cyanide plating solutions containing cadmium and copper as major constituents, 25 to 35 grams per liter, by inductively coupled argon plasma spectrometry: The spectrometric analyses were compared to the results obtained by classical volumetric chemical procedures, and it was determined that the precision (and accuracy) with this instrument are sufficient to use these methods for the control of cadmium and copper in cyanide plating solutions.

$\mathrm{BB}: 1$ js

TR4/67 


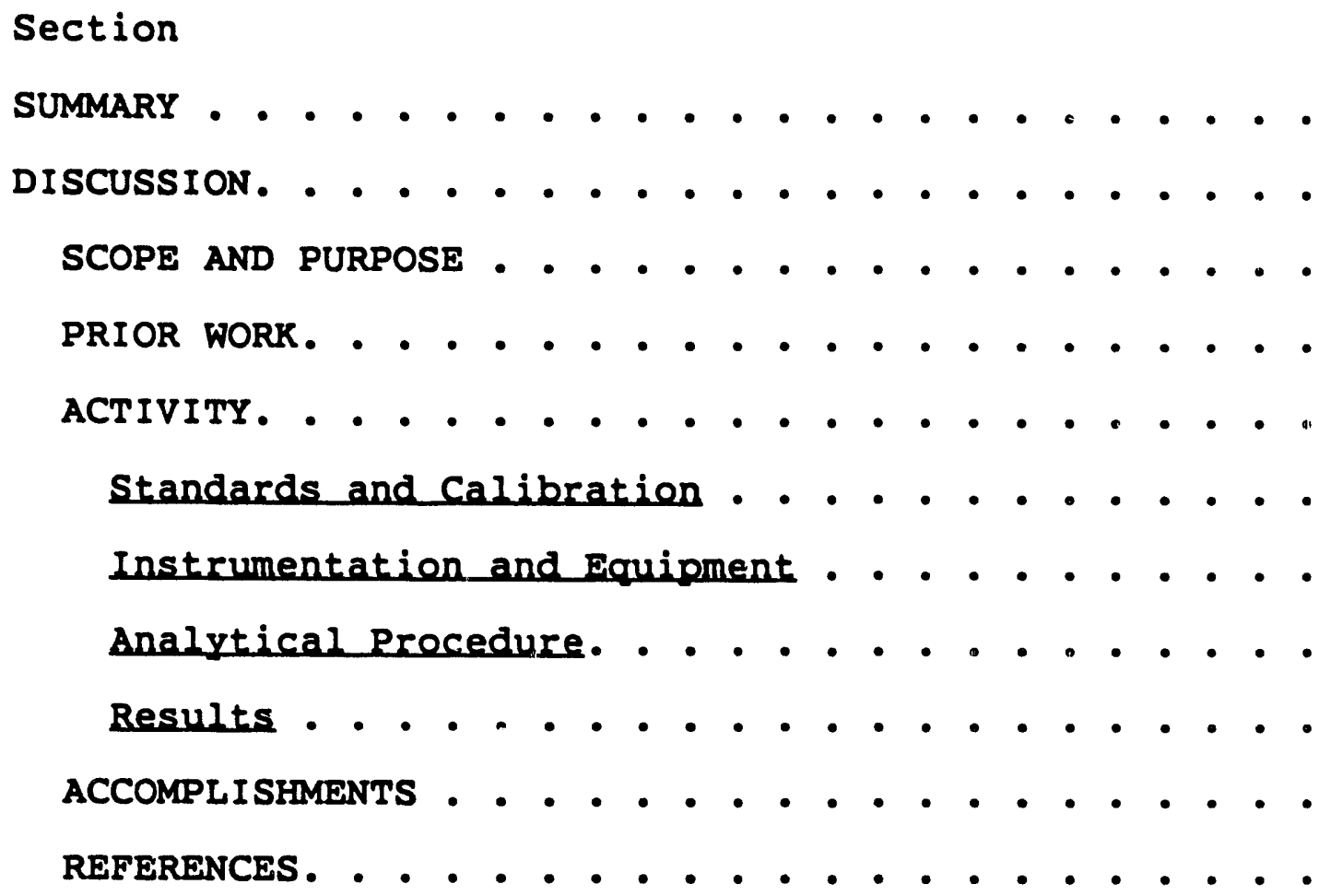




\section{ILLUSTRATIONS}

Figure

Page

1. . Copper Peak at $324.75 \mathrm{~nm}$. . . . . . . . .

\section{TABLES}

Number

Page

1

Analysis of Cadmium Metal in Cyanide

Plating Solution. . . . . . . . . . . .

2

Analysis of Copper Metal in Cyanide Plating

Solution. . . . . . . . . . . . . . . 
The purpose of this work was to develop spectrometric methods for the analysis of copper and cadmium in cyanide plating solutions. If the methods were faster and/or more accurate than the classical volumetric methods being used, spectrometric methods could replace volumetric methods for routine production support.

Spectrometric methods were developed on an inductively coupled argon plasma spectrometer. Statistical data was accumulated, allowing the precision, accuracy, and confidence levels to be calculated. The percent relative standard deviation ranged from 0.197 to 0.642 for a $35 \mathrm{~g} / \mathrm{L}$ standard for cadmium and from 0.234 to 0.743 for a $50 \mathrm{~g} / \mathrm{L}$ standard for copper, both at a $95 \%$ confidence level.

The spectrometric method developed for copper analys is proved as accurate as the classical chemical method, and faster, 20 minutes compared to two or three hours. Because of this significant savings, along with the reliability, the new method has replaced the classical method for routine production support. In contrast, the spectrometric method for cadmium proved to be slower, 30 minutes compared to 10 minutes, than the classical method. The spectrometric method is, however, accurate and reliable and will be retained as an alternate back-up method. 


\section{DISCUSSION}

\section{SCOPE AND PURPOSE}

The demand for process solution analysis and control is constantly growing, but the available workforce remains constant or diminishes. Therefore, faster and more reliable analytical methods must be developed to support such a demand. Presently, the cadmium and copper concentrations of cyanide plating solutions are routinely determined by relatively tedious classical procedures. These procedures were considered good candidates for replacement by a faster and possibly more accurate method. Because of their hazardous nature, cyanide solutions also require special handing and processing care, which could be avoided by spectrometric methods. Quick analysis response, 30 minutes or less, not only guarantees more efficient utilization of laboratory resources but helps minimize production delays caused by slow response.

\section{PRIOR WORK}

Inductively coupled argon plasma spectroscopy (ICP) has been successfully used at the Kansas City Division of Allied-signal Inc. for the analysis of different metals, including cadmium and copper, in processing solutions and other materials.1,2 Cadmium and copper cyanide plating solutions had not been investigated previously. These solutions are presently analyzed by a classical volumetric method using EDTA (ethylenediaminetetraacetic acid) as a titrant. The cadmium in cyanide plating solutions can be titrated without difficulty, but not copper. The cyanide must be destroyed before the copper metal can be determined using EDTA. This operation requires two or three hours to complete and must be performed in a hood since strong mineral acid is added to the cyanide plating solution, releasing toxic hydrogen cyanide gas.

\section{ACTIVITY}

\section{standards and Calibration}

The standard solutions used to calibrate the ICP were prepared by diluting standard solutions obtained from the National Bureau of standards (NBS). NBS \#3114, containing $10 \mathrm{mg} / \mathrm{mL}$ of copper, was used to prepare the copper calibration standards; and NBS \#3108, containing $10 \mathrm{mg} / \mathrm{mL}$ of cadmium, was used for the cadmium calibration standard. Standards containing $10 \mathrm{ppm}$ (parts per milition) and $50 \mathrm{ppm}$ copper and $70 \mathrm{ppm}$ cadmium were prepared. Because of the high concentrations of cadmium and copper in the 
plating solutions, the higher calibration standards were used to minimize the number of dilutions required to analyze the samples.

Instrumentation and Equipment

The instrument used in this work was a model IL Plasma-200 supplied by Allied Analytical Systems, Andover, MA. The spectrometer operates in the sequential mode and is controlled by a computer, using vendor-supplied software. The copper wavelength of $324.75 \mathrm{~nm}$ and cadmium wavelength of

$214.44 \mathrm{~nm}$ were used in this study. The detection limit for copper at this wavelength, in a solution containing $10 \mu \mathrm{g} / \mathrm{mL}$ of copper, is $.0054 \mu \mathrm{g} / \mathrm{mL}$; and the detection limit for cadmium, in a solution containing $10 \mu \mathrm{g} / \mathrm{mL}$ of cadmium, is $.0025 \mu \mathrm{g} / \mathrm{mL}$. These detection limits were provided in the instrument operation manual. Class A glassware was used throughout all procedures.

\section{Analytical Procedure}

An examination of the cadmium and copper peaks was made to check for interfering elements, which would require a background correction to be made. (See Figures 1 and 2.) No interferences were found.

Two sets of twelve cadmium test samples were prepared by pipetting $0.2 \mathrm{~mL}$ of plating solution into $100 \mathrm{~mL}$ volumetric flasks containing $5 \mathrm{~mL}$ of concentrated hydrochloric acid and approximately $50 \mathrm{~mL}$ of nanopure deionized water. The flasks were then diluted to the volume mark with additional deionized nanopure water and mixed well. One set was prepared with a glass pipet and the other set with an Eppendorf pipet (VWR Scientific, Chicago, IL). These two sets of samples would give an indication of pipet and flask volume differences. A $5 \%$ hydrochloric acid solution was used for the blank. Hydrochloric acid was used in all solutions to minimize any matrix interferences in the plating solution. Additional samples of the cadmium plating solution were prepared and spiked with eight $\mathrm{g} / \mathrm{L}$ of cadmium to check the recovery of the test method. Three determinations were also made using the standard classical method on the cadmium cyanide plating solution. These results were identical and were used to check the accuracy of the ICP determinations because samples of a standard cadmium plating solution were not available.

Two sets of twelve copper samples were prepared in the same manner as the cadmium samples except hydrochloric acid was not added because it caused a precipitate to form in the solution. The instrument was calibrated with $50 \mathrm{ppm}$ standard, and the two sets of twelve samples were analyzed. The instrument was then calibrated with two copper standards, $10 \mathrm{ppm}$ and $50 \mathrm{ppm}$; and the samples were analyzed again. These tests were to determine possible benefits of using a two-point calibration curve. Because a standard copper plating solution was not available, 


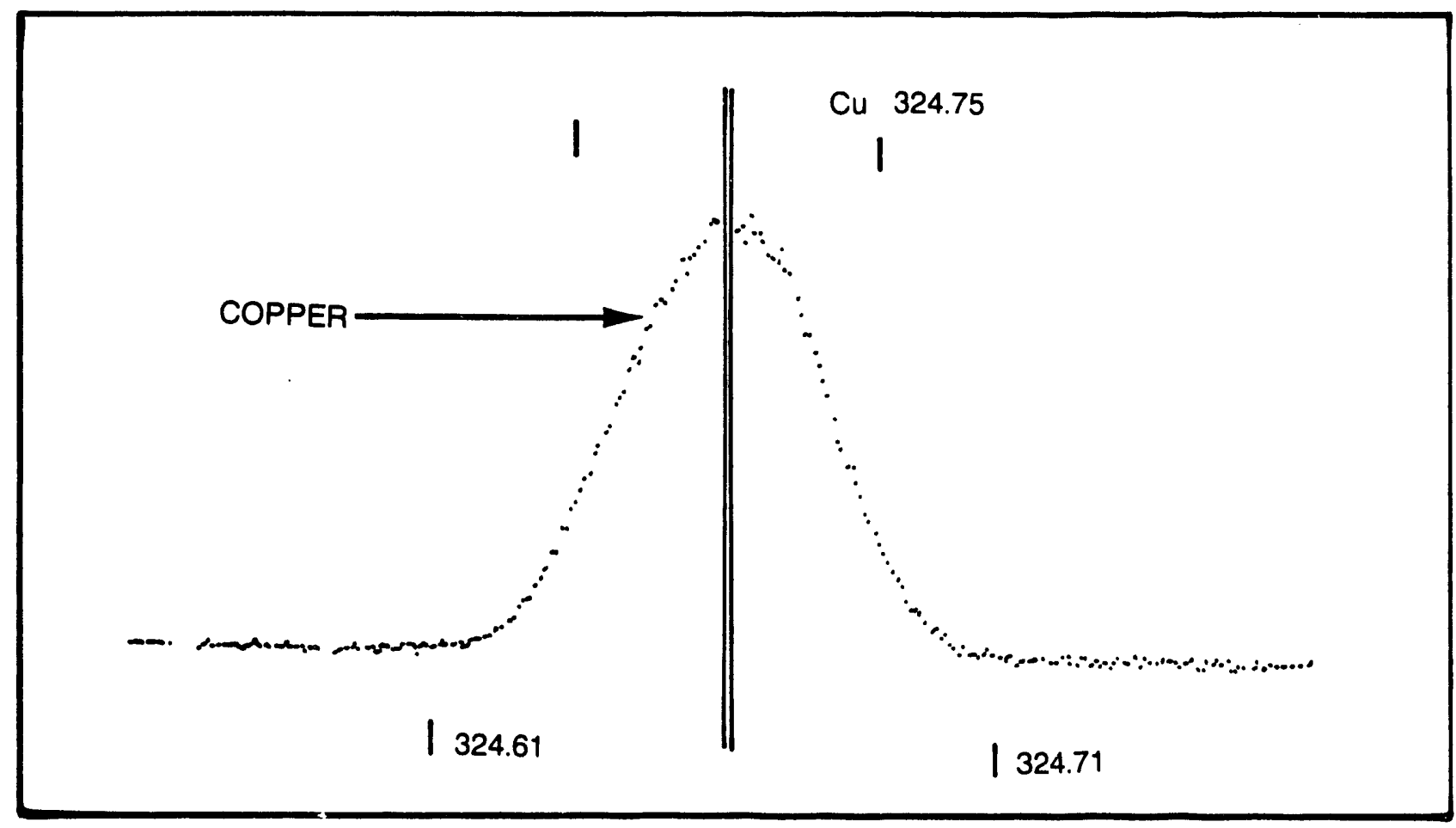

Figure 1. Copper Peak at $324.75 \mathrm{~nm}$

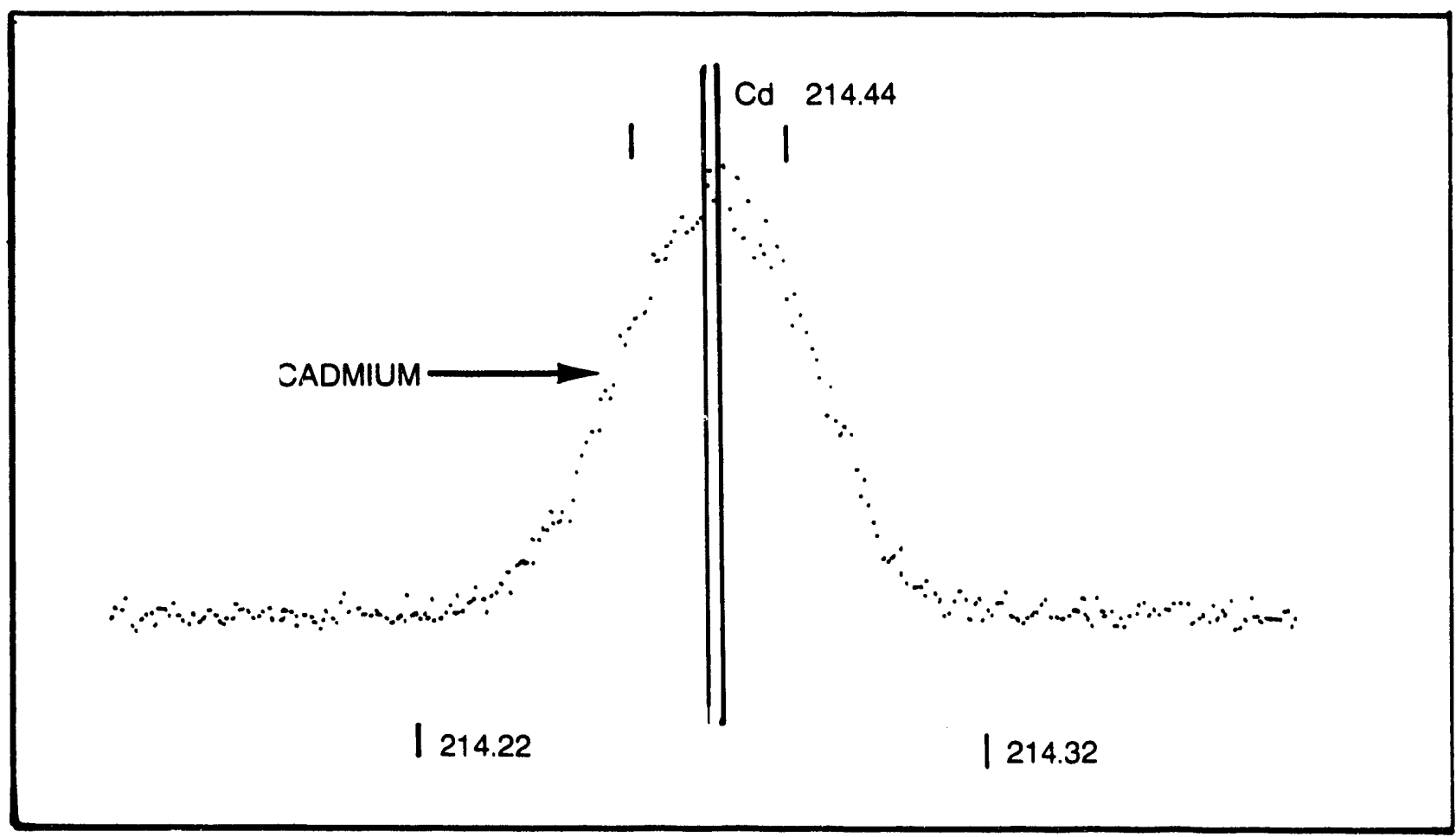

Figure 2. Cadmium Peak at $214.44 \mathrm{~nm}$ 
four samples of the copper cyanide plating solution were analyzed by the standard classical method to check the accuracy of the ICP determinations. The spectrometer was then calibrated with the 50 ppm copper standard, and twelve determinations were made using this standard as a sample to determine drift and precision of the instrument at this wavelength.

\section{Results}

Results of the cadmium analysis are listed in Table 1. The results show a difference in the glass-pipetted samples versus the Eppendorf pipet samples, but the cadmium range in the plating solution $(10 \mathrm{~g} / \mathrm{L})$ is large enough to ignore these differences. The Eppendorf pipet is faster to use, although the glass pipet is somewhat more accurate. If an analysis were near the top or bottom of the specification range, it might be advisable to recheck the sample using the glass pipets, if the original analysis had been performed with an Eppendorf pipet. The results of the samples that were spiked with cadmium were very close to the theoretical values, with a recovery of 99.57\%. This recovery figure indicates that the method is viable for plating solution analysis. Although the accuracy is good, this method will not replace the classical method because it takes more time to set up and calibrate the ICP than it does to analyze the cadmium by the classical method.

Results of the copper analysis are listed in Table 2. As with the cadmium, the two types of pipets were used; but the relative accuracy differences were small and could be ignored. One-point and two-point calibration curves were generated for use in this copper determination. Although two-point calibration was more precise, results did not differ enough to justify spending the time required to use a two-point calibration curve. The specification range for the copper content $(8 \mathrm{~g} / \mathrm{L})$ is not as great as with the cadmium solution, but this method with a onepoint calibration curve will work satisfactorily. In the classical method, the cyanide must be destroyed before the copper can be determined with the EDTA. This process takes approximately two or three hours to complete compared to about 20 minutes for the complete ICP analysis.

During these evalutions, the spectrometer was stable for three or four determinations and then would very slowly drift in calibration. When evaluating more than four samples, the instrument should be recalibrated after every four samples for greater accuracy. In most applications, this procedure would not be a problem because plating shops seldom have more than one or two of these tanks i.. operation. 


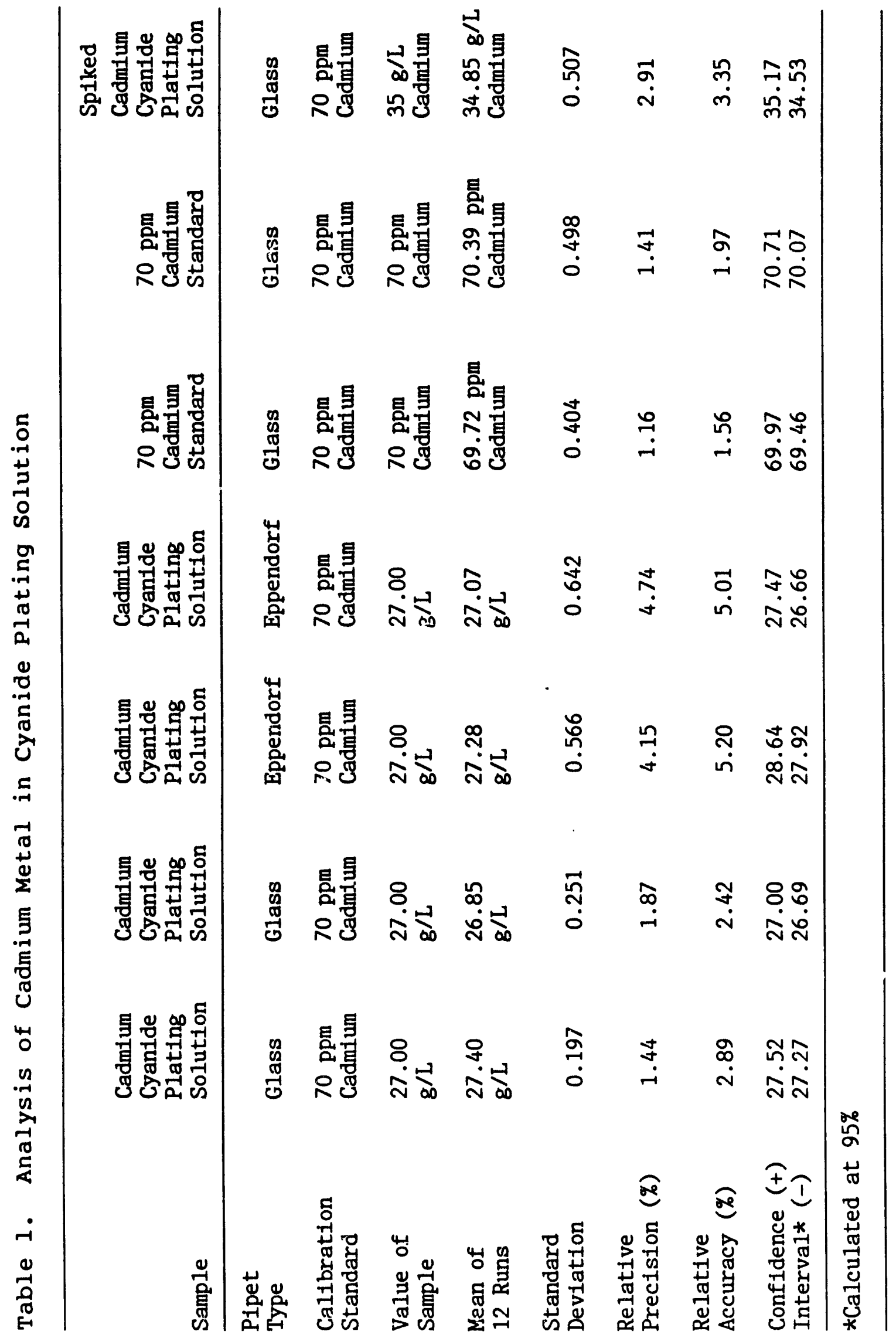




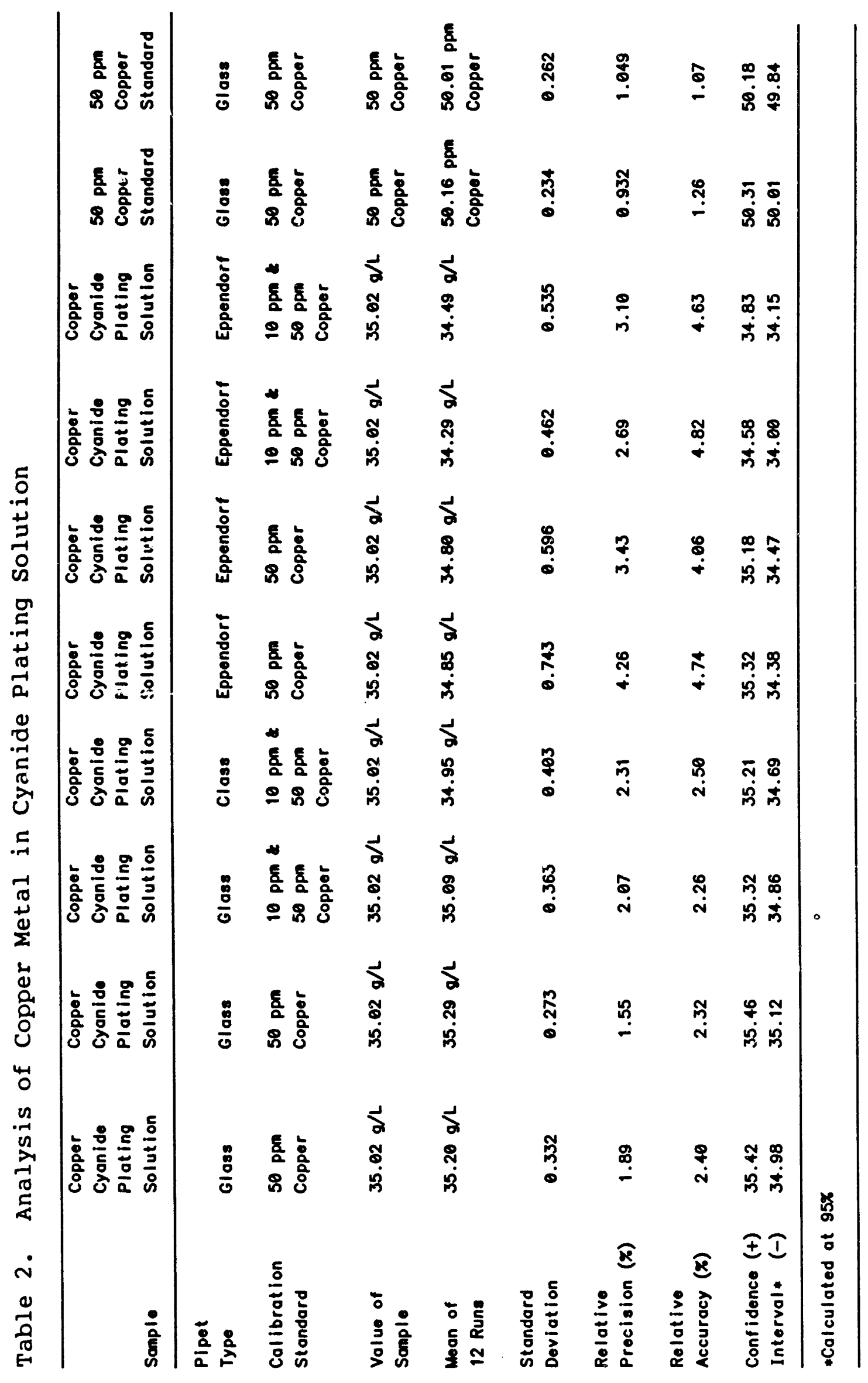




\section{ACCOMPLI SHMENTS}

Spectrometric methods have been developed for the analys is of two plating solutions. The ICP method developed for cadmium will not replace the classical volumetric method currently in use because the ICP method is not as fast or as accurate. It can, however be used as a backup method. The method developed for the determination of copper is much Tuicker than the classical method, and the accuracy is sufficient for replacement of the classical volumetric method currently used. For cases in which a referee method is required, the classical method should be used because it has higher accuracy than its spectrometric counterpart. 


\section{REFERENCES}

${ }^{2} \mathrm{H}$. Reimer, Analysis of Low Alloy and Stainless steels by Inductively coupled Argon Plasma spectrometer (Topical Report). Kansas City Division: KCP-613-4032, November 1988. (Available from NTIS).

${ }^{2} \mathrm{H}$. Reimer, Plating and Plating Solution Analysis by Inductively Coupled Argon Plasma spectrometer (Topical Report). Kansas City Division: BDX-613-3686, February 1987. (Available from NTIS). 

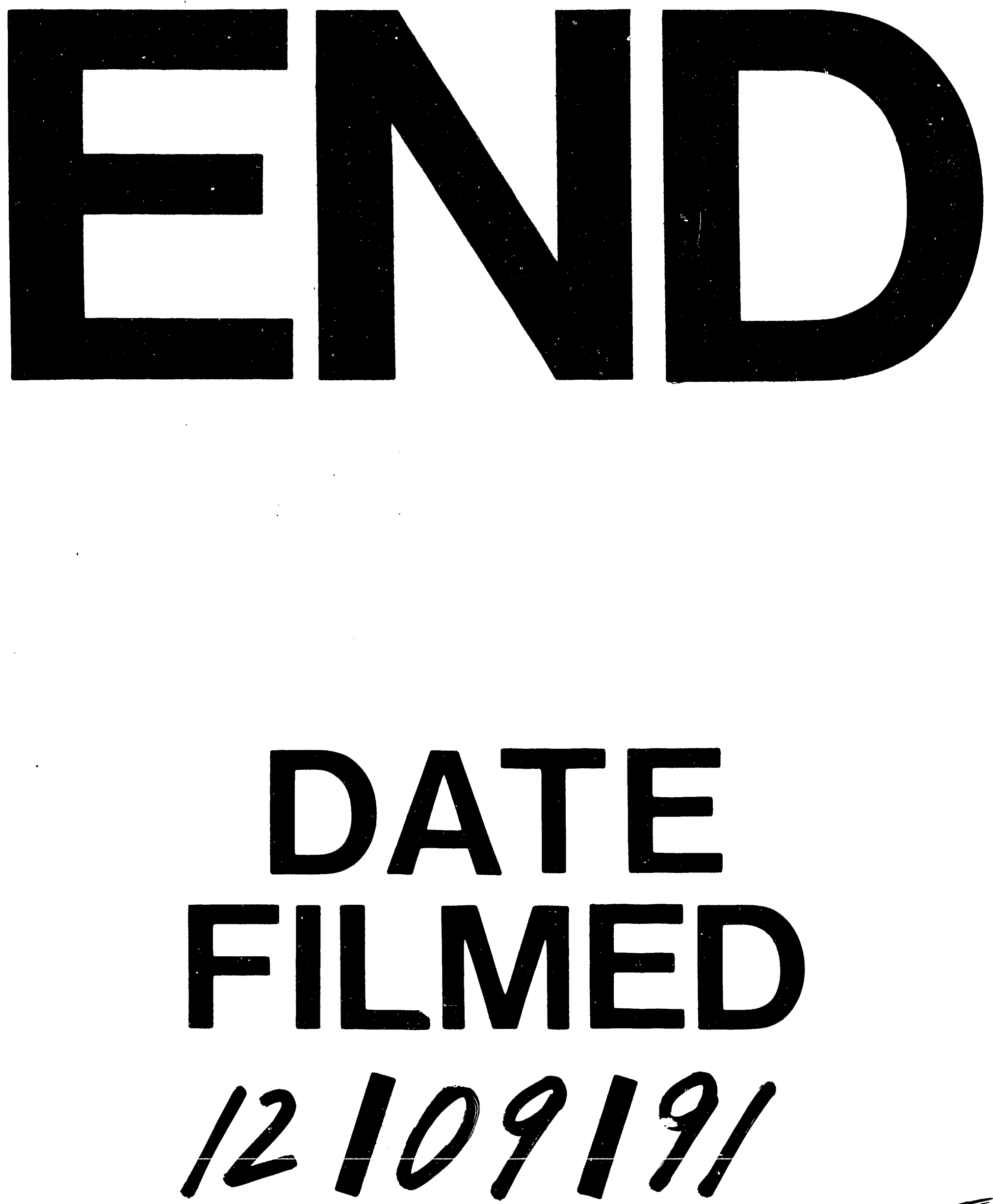

1 
$=$ 